Research Article

\title{
Damage Boundary Study of Crystal Oscillators under Shock Environment
}

\author{
Changjian Zhao, ${ }^{1}$ Zijun Zhang, ${ }^{1}$ Zijian Xu, ${ }^{1,2}$ Bingwei Li $\mathbb{D}^{1},{ }^{1}$ Muchun Yu, ${ }^{1}$ and Zhiling Niu ${ }^{1}$ \\ ${ }^{1}$ China Academy of Launch Vehicle Technology, Beijing 100076, China \\ ${ }^{2}$ State Key Laboratory of Explosion Science and Technology, Beijing Institute of Technology, Beijing 100076, China
}

Correspondence should be addressed to Bingwei Li; bingweili@163.com

Received 28 March 2020; Revised 8 July 2020; Accepted 15 July 2020; Published 6 August 2020

Academic Editor: Giuseppe Petrone

Copyright (C) 2020 Changjian Zhao et al. This is an open access article distributed under the Creative Commons Attribution License, which permits unrestricted use, distribution, and reproduction in any medium, provided the original work is properly cited.

\begin{abstract}
The crystal oscillator is a widely used electronic component in a circuit, whose accuracy is strongly affected by the external mechanical environment. To depict the failure mechanism of the crystal oscillator, the damage boundary of this component under the shock environment is studied experimentally in this paper. Through subjecting "step-up" loads on different groups of crystal oscillators, two failure modes (frequency jumping and structural fracture) are monitored and validated. Experimental results prove that "frequency jumping" failure mode is governed by the value of the acceleration shock response spectrum (ASRS) in a certain frequency range, while the failure mode "structural fracture" is governed by the peak value of the ASRS. Through analyzing the shock response spectrum, damage boundaries are given for these two failure modes, which can provide a reference for component design and failure assessment.
\end{abstract}

\section{Introduction}

As an essential electric component, the crystal oscillator generates a signal at a stable frequency, which provides a basic clock for the whole circuit [1]. This mechanism is widely used in various fields such as surveillance, communication, navigation, aeronautics, and astronautics [1]. The crystal plate is the kernel structure of a crystal oscillator, which is easily affected by external shock environment $[2,3]$. The dynamic characteristics of the crystal plate will change and structural damage may occur under shock environment, causing the output signal to be abnormal, which seriously affects the reliability of the crystal oscillator.

At present, the dynamic response of the crystal oscillator under the shock environment has drawn wide attention. Li et al. [4] selected two types of crystal oscillators for shock experiments, and the results showed that the internal structure of the crystal oscillator directly affected its shock resistance. The performance of the crystal plate placed parallel to the direction of propagation of the stress wave was better than that perpendicular to the direction of propagation of the stress wave. Qi et al. [2] studied the common quartz crystal oscillator through establishing the shock dynamic response model and considering the equivalent electric power conversion characteristics, and then the failure mechanism of the crystal oscillator under shock environment was qualitatively analyzed and verified by experiment. Xu [3] analyzed the shock failure mechanism of crystal oscillator through the Hopkinson experiment, and the results showed that the crystal plate might be broken under high acceleration shock, which leads to an inevitable failure of the crystal oscillator.

Damage boundary refers to the envelope of the shock response spectrum which causes critical failure of the crystal oscillator. The research of the damage boundary for structures under the shock environment has received much attention nowadays. Researchers experimentally studied the damage boundary of a metal beam under uniformly distributed impact loads [4-6]. Based on these studies, Jones et al. [7] proposed failure criteria by theoretically analyzing the rigid plasticity of the beam. Shen and Jones [8] proposed the energy density assessment criterion of the rigid-plastic 
structure. Wen et al. [9-11] studied the failure of a fixed beam and a circular plate in shock environment and proposed the damage boundary governed by quasi-static equivalent energy. However, due to the structural complexity of the crystal oscillator, these results cannot be applied directly.

On the basis of high stress damage failure, pseudovelocity has been used to denote the damage boundary of structures [12-15]. Pseudovelocity damage boundary considers that if the maximum pseudovelocity responses of a structure are the same, the stress level and the damage on the structure are equivalent; even the external shock loads are quite different [16-19]. Gaberson and Chapler [20] used different types of shock loads to perform experiments on a wind turbine, which proved that the pseudovelocity response could effectively characterize the severity of the shock environment. If the maximum pseudovelocity response reaches a critical value, failure would occur on the fans of the turbine; even the acceleration responses are quite different. However, the premise of utilizing pseudovelocity damage boundary is that the dominant frequency of the shock excitation is closed to the natural frequency of the structure. If the natural frequency of the structure differs greatly from the dominant frequency of the shock excitation, this theory will no longer be applicable [21].

The failure mode and damage boundary of crystal oscillator under shock environment are still unclear. In order to ensure the reliability and environmental adaptability of the electronic devices, it is urgent to study the failure mechanism and build the failure criterion of the crystal oscillator. In this paper, a simplified mechanical model is established based on the working principle of a quartz crystal oscillator. The dynamics response and damage boundary under shock environment are established and further verified through shock experiments, which can prove some reference for the design of electronic devices.

\section{Failure Mechanism of the Crystal Oscillator}

2.1. Failure Mode 1: Frequency Jumping. Under normal circumstances, the output frequency of the crystal oscillator is constant. When there exists a shock excitation, the output frequency may "jump" and affect the function of the oscillator.

The structure of the crystal oscillator is shown in Figure 1; two metallic electrodes are attached to the crystal plate. The external controlling circuit places the crystal plate into an unstable equilibrium. Due to the positive feedback in the system, any tiny fraction of noise will be amplified, ramping up the oscillation. Piezoelectric resonance occurs on the crystal plate when the frequency of the alternating voltage is closed to the natural frequency of the crystal plate, as shown in Figure 2.

The crystal oscillator working at the frequency related to the piezoelectric resonance. As the oscillator amplifies the vibration signals of the crystal plate, as shown in Figure 3(a) and $3(\mathrm{~b})$, the working frequency of the crystal oscillator will not change under an external excitation which is relatively weaker than the resonance vibration of the oscillator.

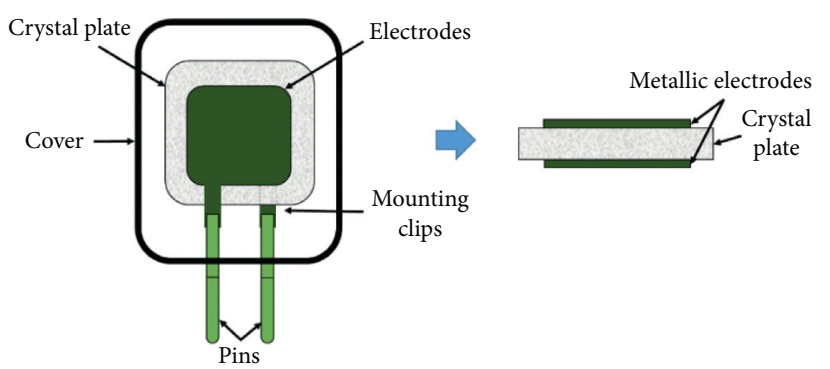

Figure 1: Model of the crystal oscillator.

But when the energy of the external excitation is sufficiently high, the noise vibration of the crystal plate will not be filtered, and then the frequency of the output signal will change. Under these circumstances, a "frequency jump" will be monitored in the output signal.

As shown in Figure 4, the working frequency of the oscillator will change with a tendency to the dominant frequency $f$ of the response caused by external shock excitation. Therefore, the damage criterion corresponding to this failure mode can be expressed as

$$
V(f)>V_{c f} \Longleftrightarrow a(f)>a_{c f 1} .
$$

It should be noted that the "frequency jumping" failure is recoverable because structural damage does not occur on the crystal plate. The output frequency will return to normal when the external shock excitation is withdrawn, as shown in Figure 5.

2.2. Failure Mode 2: Structural Fracture. When the external shock excitation is sufficiently large, high stress will be generated on the crystal plate, leading to the structural damage.

As shown in Figure 6, the relation between the maximum stress $\sigma_{m}$ on the crystal plate and the relative acceleration $a$ can be expressed as

$$
\sigma_{m}=\frac{\rho b d^{2} l^{2}}{4 I_{z}} a,
$$

where $\rho$ and $I_{z}$ denote the density and inertia moment of the crystal plate, respectively. $a$ denotes the acceleration relative to the foundation of the plate, which causes the inertia force of the crystal plate.

Then, the damage boundary related to the structural fracture can be expressed as

$$
\sigma_{m}>\sigma_{b} \Longleftrightarrow a>a_{c f 2} .
$$

It can be obtained from equation (2) that the high stress of the crystal plate is related to the geometric profile, boundary condition, and the peak value of the relative acceleration $a$. The relative acceleration can be represented as the acceleration shock response spectrum (ASRS) of the foundation. Hence, it can be concluded that the structural fracture of the crystal plate is governed by ASRS of the shock excitation. 

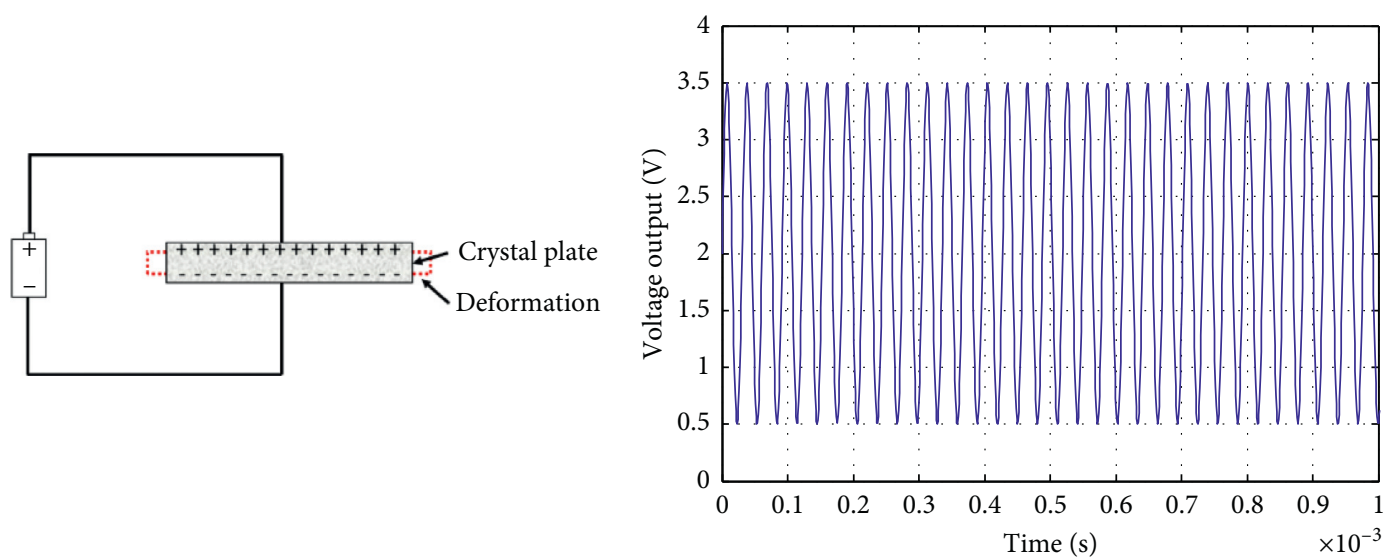

Figure 2: Piezoelectric resonance of the crystal plate.

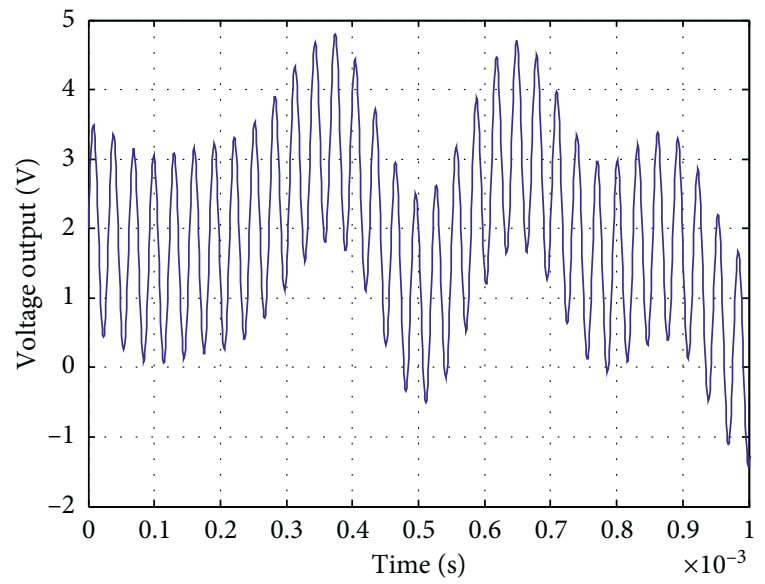

(a)

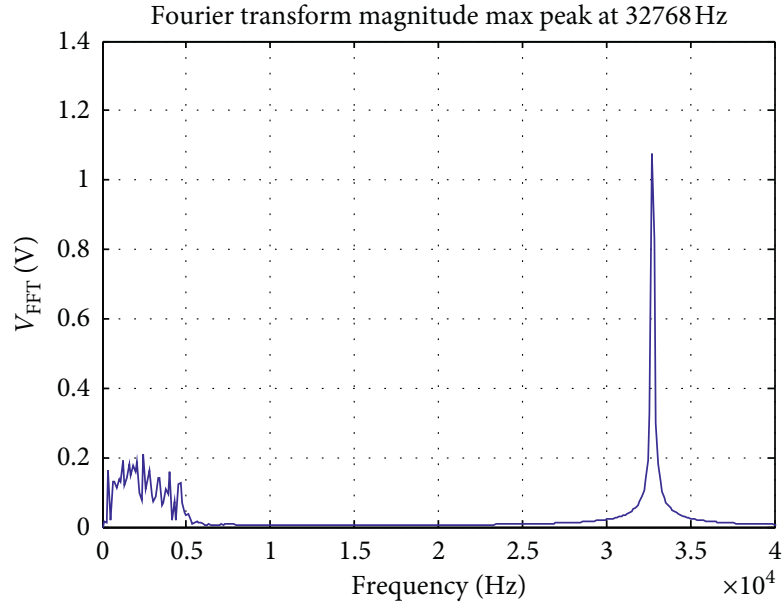

(b)

FIGURE 3: Output signal of the crystal oscillator under external excitation. (a) Signal with noise. (b) Signal in the frequency domain.

\section{Experiment Verification}

3.1. Experiment Scheme. To consider the uncertainty of different specimens, eight crystal oscillators are fixed on the same printed circuit board (PCB), distributing uniformly, as shown in Figure 7.

Two groups of loads are designed and applied to two different PCBs: C1 board and C2 board, in order to investigate the influence of different inflection frequencies on the failure of the crystal oscillator. Shock loads are applied to the specimen through a "gas-gun" device as shown in Figure 8.

In order to determine the critical damage boundary of the crystal oscillators, the shock loads are designed as "stepup" with an increasing tendency, as listed in Tables 1 and 2.

Pseudovelocities of the loads in Table 2 are similar to those in Table 1, while the peak acceleration and the inflection frequencies are different. This contrast is designed to validate whether the damage boundary is governed by the peak acceleration shock response spectrum (ASRS) or the peak pseudovelocity shock response spectrum (PVSRS).

3.2. Data Acquisition. Four acceleration sensors are distributed uniformly on the PCB to monitor the acceleration response spectrum of the specimens, as shown in Figure 9. The mass property of the sensor is listed in Table 3.

The acceleration response of the PCB is monitored by the sensor in the time domain. These time-domain data are transformed to the shock response spectrum (SRS) through an embedded program in the data acquisition equipment, as shown in Figure 10.

The working frequency of the crystal oscillator is monitored through a sampling calculation on the signal in the time domain, so the length of the sampling will limit the accuracy of the experiment results. In this experiment, the length of sampling is set to be $5 \mathrm{~ms}$, and the output frequency is set as the average value of the oscillating frequency in the 


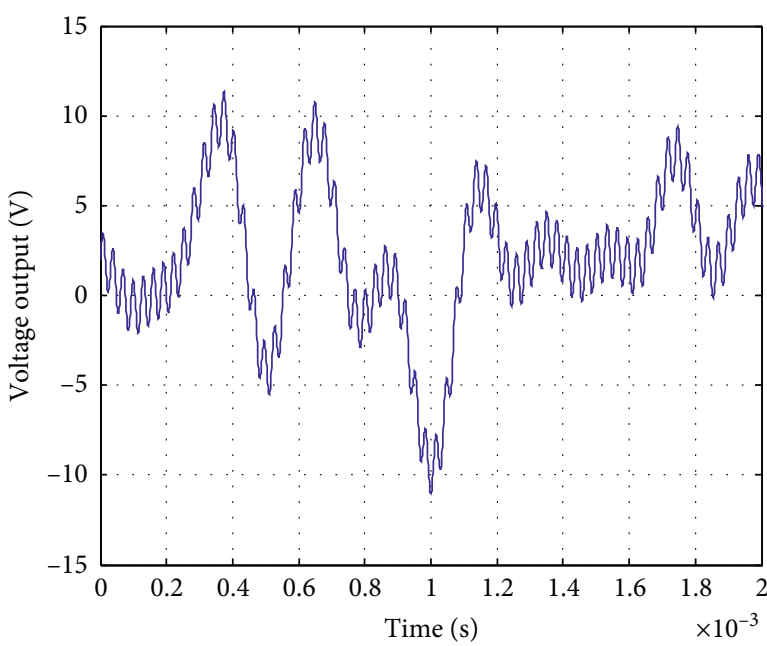

(a)

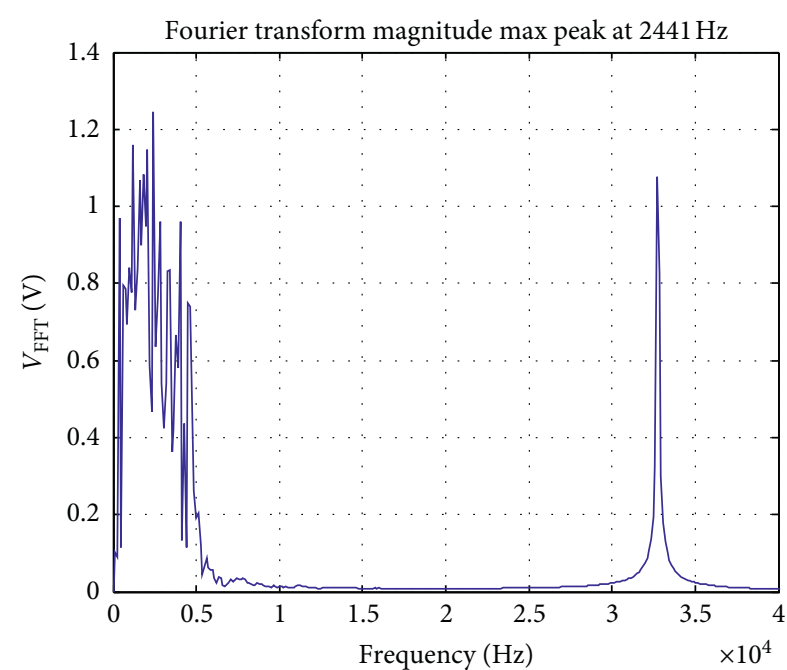

(b)

FIGURE 4: Frequency jumping of the crystal oscillator under external shock excitation. (a) Signal with noise. (b) Signal in the frequency domain.

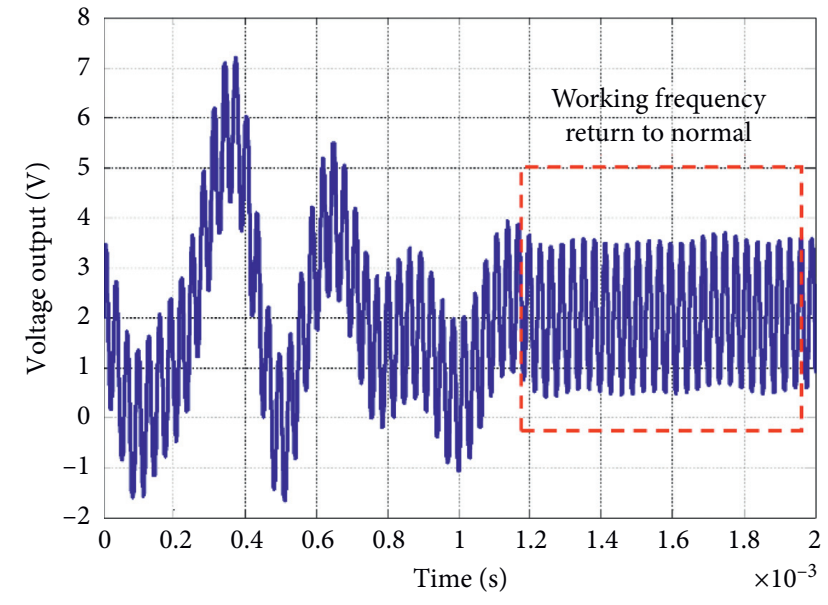

FIGURE 5: Recoverable frequency jumping of the oscillator.

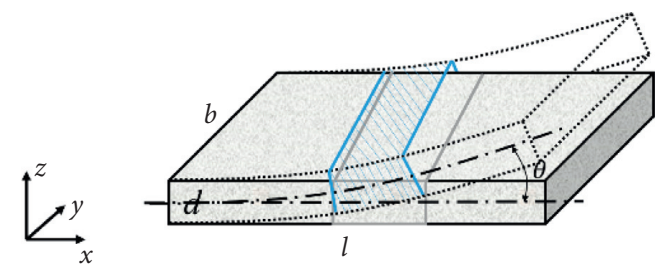

FIGURE 6: The deformation of the crystal plate under external excitation.

sampling range. Thus, the output frequency deviation monitored during the shock loading process will be an instantaneous change rather than a continuous change.

It should be noted that the mass of the acceleration sensor has little influence on the results of the experiment. The acceleration sensors and the PCB are considered as an entirety in the experiment. Although the

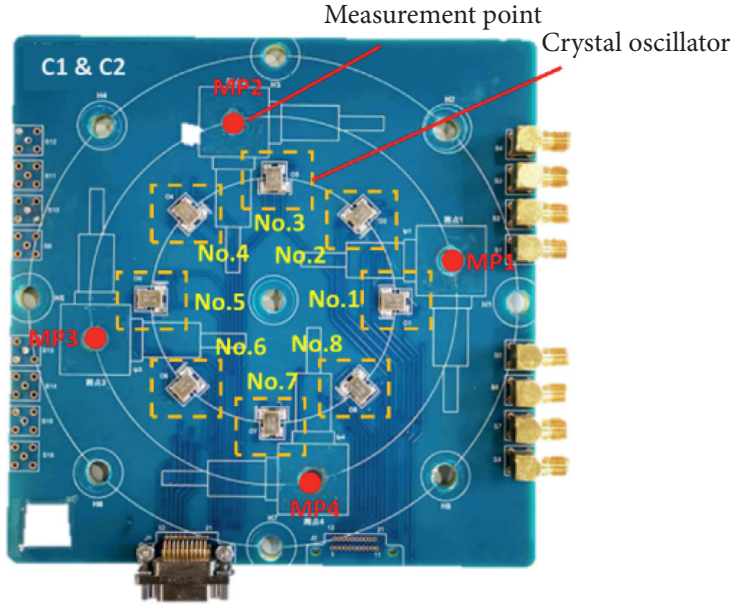

Figure 7: Crystal oscillators distributed on the PCB.

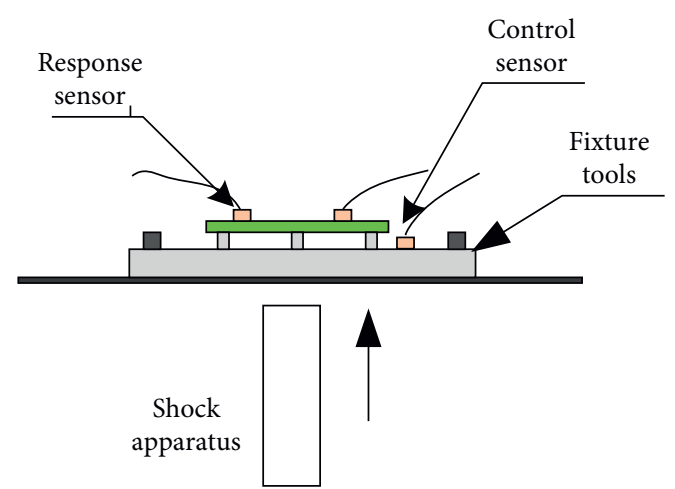

FIGURE 8: Sketch of the experiment process.

peak acceleration varies in a big range, the monitored response of the crystal oscillator has included the response of the sensor. The measuring error caused by the 
TABle 1: Shock loads on C1.

\begin{tabular}{lccc}
\hline Loading step & Inflection frequency $(\mathrm{Hz})$ & Peak acceleration $(\mathrm{g})$ & Peak pseudovelocity $(\mathrm{m} / \mathrm{s})$ \\
\hline Step 1 & 700 & 500 & 1.12 \\
Step 2 & 700 & 1500 & 3.36 \\
Step 3 & 700 & 2500 & 5.60 \\
Step 4 & 700 & 3500 & 7.84 \\
Step 5 & 700 & 4500 & 10.08 \\
Step 6 & 700 & 5500 & 12.32 \\
Step 7 & 700 & 6500 & 14.56 \\
Step 8 & 700 & 7500 & 16.80 \\
Step 9 & 700 & 8500 & 19.04 \\
Step 10 & 700 & 9500 & 21.28 \\
Step 11 & 700 & 11000 & 24.63 \\
Step 12 & 700 & 12000 & 26.87 \\
Step 13 & 700 & 13000 & 29.11 \\
\hline
\end{tabular}

TABLE 2: Shock loads on C2.

\begin{tabular}{lccc}
\hline Loading step & Inflection frequency $(\mathrm{Hz})$ & Peak acceleration $(\mathrm{g})$ & Peak pseudovelocity $(\mathrm{m} / \mathrm{s})$ \\
\hline Step 1 & 2000 & 1500 & 1.18 \\
Step 2 & 2000 & 4000 & 3.14 \\
Step 3 & 2000 & 7000 & 5.49 \\
Step 4 & 2000 & 10000 & 7.84 \\
Step 5 & 2000 & 13000 & 10.19 \\
Step 6 & 2000 & 16000 & 12.54 \\
Step 7 & 2000 & 19000 & 14.89 \\
Step 8 & 2000 & 22000 & 17.24 \\
Step 9 & 2000 & 25000 & 19.60 \\
Step 10 & 2000 & 28000 & 21.95 \\
Step 11 & 2000 & 31000 & 24.30 \\
Step 12 & 2000 & 34000 & 26.65 \\
Step 13 & 2000 & 37000 & 29.00 \\
\hline
\end{tabular}

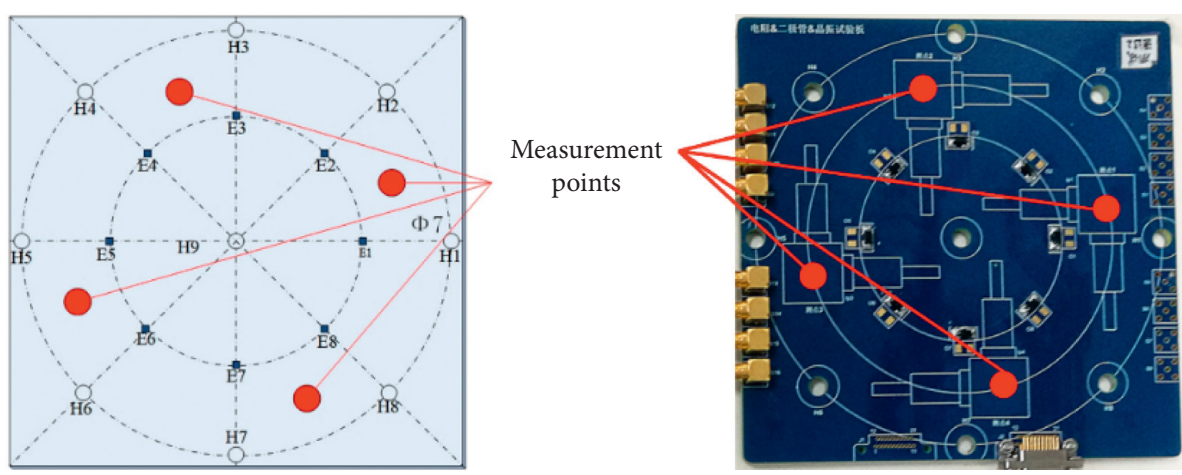

FIGURE 9: Distribution of measurement points.

TABLE 3: The mass property of the acceleration sensor.

\begin{tabular}{lccc}
\hline Name & Model & Mass $(\mathrm{kg})$ & Geometry profile \\
\hline Acceleration sensor & Big vibration measuring model 21105 & 0.013 & $\Phi 6 \mathrm{~mm} \times 30 \mathrm{~mm}$ \\
\hline
\end{tabular}

acceleration sensor originates from the following two aspects:

(1) The mass of the acceleration sensor has a certain influence on the dynamic characteristics of the PCB. Through modal analysis of the PCB with sensors, it is found that the influence of the sensor mass on the
PCB is mainly concentrated in the range of $1400 \mathrm{~Hz} \sim 2500 \mathrm{~Hz}$, as shown in Table 4. This frequency is quite different from the natural frequency of the crystal oscillator. However, the main goal of this study is to determine the damage boundary under the shock environment of the electronic 


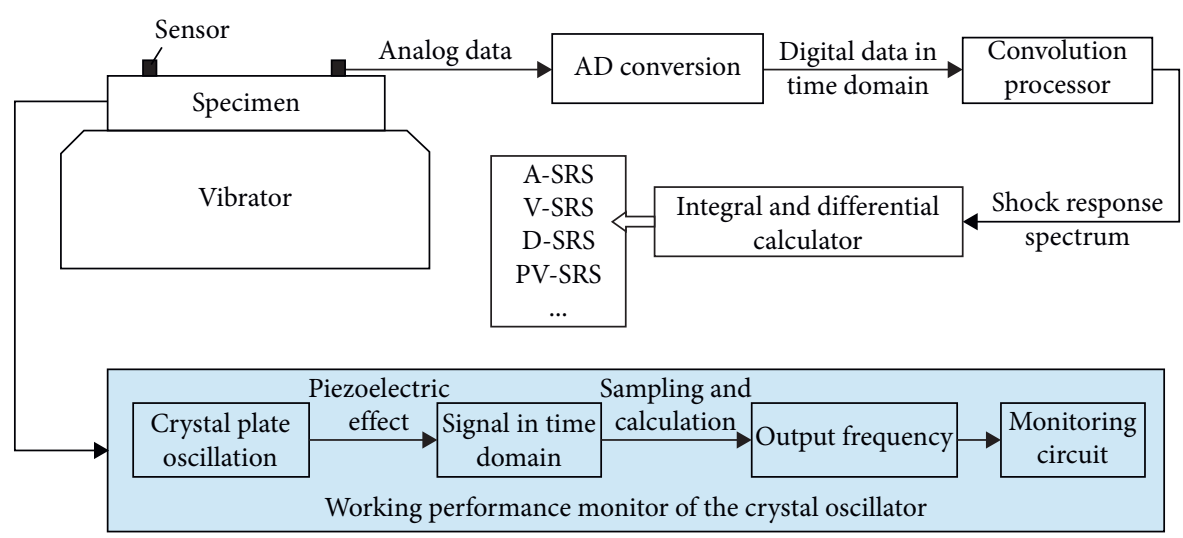

FIgURE 10: Data acquisition process in the experiment.

TABLe 4: Natural frequencies and modals of the PCB (including sensors).

$\begin{aligned} & \text { Modal } \\ & \text { order }\end{aligned}$
$2^{\text {nd }}$
$3^{\text {rd }}$
$4^{\text {th }}$

components. Therefore, the difference caused by the mass of the sensor does not affect the failure modes or damage boundary of the crystal oscillator, as long as the shock environment is measured accurately. In this study, the selected sensors are calibrated before the test and the shock response measured by the sensors is accurate enough

(2) In this study, the shock loads with different dominant frequencies are applied to PCBs $\mathrm{C} 1$ and $\mathrm{C} 2$, in order to determine whether the failure mode of the crystal oscillator is controlled by ASRS or PVSRS. The failures of different crystals on each PCB are monitored separately during the test. The test error due to the different mounting positions of the crystal does not affect the test results. During the test, the response of the crystal oscillator was monitored by noncontact measurement (laser) and compared with the monitoring value of the acceleration sensor, as shown in Figure 11. It can be seen that the deviation between the SRS measured by the sensor and the noncontact measurement does not exceed $3 \mathrm{~dB}$ within the full frequency range $(20 \mathrm{~Hz} 10000 \mathrm{~Hz})$. Therefore, it can be concluded that the measurement deviation due to the distance between the acceleration sensor and the crystal oscillator does not affect the experiment result

\section{Results and Discussion}

4.1. Experiment Results. During the experiment, the level of the shock load is increased until failure occurs on the crystal oscillator. The shock response on the PCB increases gradually, as listed in Tables 5 and 6, and the performance of those crystal oscillators is monitored through the external test equipment.

On the $\mathrm{C} 1$ board, frequency jumping occurs on crystal oscillators (No. 2 and No. 4) when the peak value of ASRS reaches about $2500 \mathrm{~g}$. The number of failure oscillators increases with the increase of the excitation level. When the ASRS reaches about $13000 \mathrm{~g}$, unrecoverable frequency deviation starts to appear on the crystal oscillators (No. 8 is the first component on which unrecoverable failure occurs).

Results on C2 board represent a similar trend: when the peak value of ASRS reaches about $2500 \mathrm{~g}$, recoverable frequency jumping occurs on one of the eight crystal oscillators (No. 7), and when the ASRS reaches about $15000 \mathrm{~g}$, unrecoverable frequency deviation begins to occur on the oscillators.

It should be noted that there exist some drawbacks. Experiments on the C2 board after Step7 are not conducted because of the limitation of the "gas-gun" device. Besides, the shock loads are generated through an open-loop control 


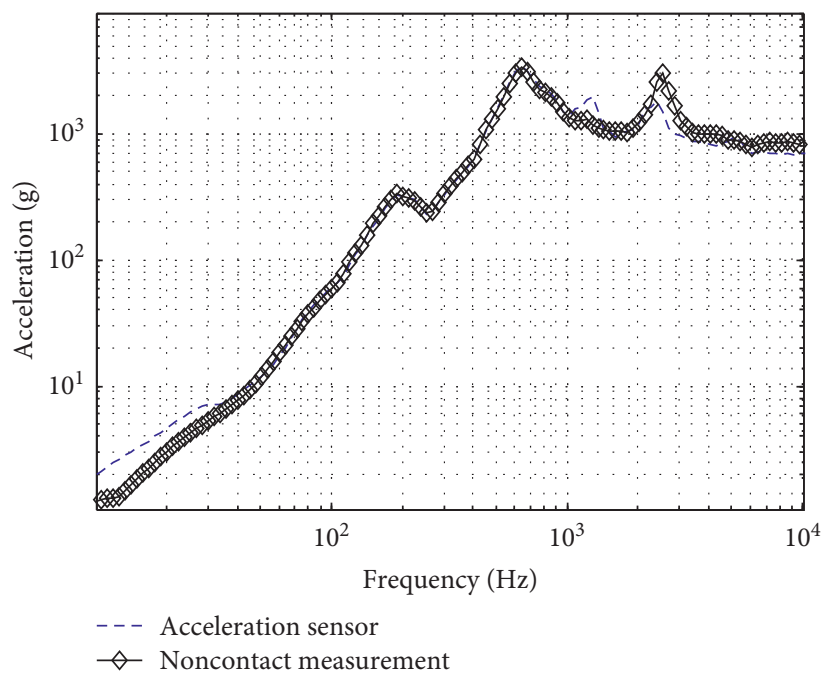

FIgURE 11: The error caused by the deviation in the measurement position.

TABle 5: Performance of crystal oscillators on the C1 board.

\begin{tabular}{|c|c|c|c|c|}
\hline Loading step & Inflection frequency $(\mathrm{Hz})$ & Peak ASRS (g) & Peak PVSRS $(\mathrm{m} / \mathrm{s})$ & Test results \\
\hline Step 1 & 616 & $624 \sim 630$ & $1.44 \sim 1.61$ & $\mathrm{~N}$ \\
\hline Step 2 & 695 & $965 \sim 1079$ & $2.22 \sim 2.48$ & $\mathrm{~N}$ \\
\hline Step 3 & 658 & $2418 \sim 2629$ & $5.89 \sim 6.41$ & $\mathrm{~N}$ \\
\hline Step 4 & 680 & $3149 \sim 3431$ & $7.67 \sim 8.36$ & $\mathrm{R}$ \\
\hline Step 5 & 691 & $4086 \sim 4481$ & $10.21 \sim 11.08$ & $\mathrm{R}$ \\
\hline Step 6 & 690 & $4866 \sim 5289$ & $12.69 \sim 13.82$ & $\mathrm{R}$ \\
\hline Step 7 & 626 & $6286 \sim 6871$ & $16.88 \sim 18.53$ & $\mathrm{R}$ \\
\hline Step 8 & 621 & $7628 \sim 8384$ & $20.87 \sim 22.93$ & $\mathrm{R}$ \\
\hline Step 9 & 698 & $8168 \sim 8891$ & $23.67 \sim 26.06$ & $\mathrm{R}$ \\
\hline Step 10 & 693 & $9438 \sim 11200$ & $27.23 \sim 29.99$ & $\mathrm{R}$ \\
\hline Step 11 & 631 & $12320 \sim 13240$ & $34.21 \sim 35.32$ & $\mathrm{R}$ \\
\hline Step 12 & 636 & $13150 \sim 16750$ & $38.03 \sim 42.75$ & $\mathrm{R}$ \\
\hline Step 13 & 612 & $13460 \sim 16660$ & $37.76 \sim 43.46$ & $\mathrm{U}$ \\
\hline
\end{tabular}

"N": normal; "R": recoverable frequency jumping; "U": unrecoverable frequency deviation.

TABLe 6: Performance of crystal oscillators on the C2 board.

\begin{tabular}{|c|c|c|c|c|}
\hline Loading step & Inflection frequency $(\mathrm{Hz})$ & Peak ASRS (g) & Peak PVSRS $(\mathrm{m} / \mathrm{s})$ & Test results \\
\hline Step 1 & 2255 & $1432 \sim 1903$ & $1.31 \sim 1.42$ & $\mathrm{~N}$ \\
\hline Step 2 & 2001 & $2468 \sim 2925$ & $1.81 \sim 2.18$ & $\mathrm{R}$ \\
\hline Step 3 & 2363 & $4278 \sim 4907$ & $3.11 \sim 3.66$ & $\mathrm{R}$ \\
\hline Step 4 & 2041 & $7072 \sim 8042$ & $5.21 \sim 6.14$ & $\mathrm{R}$ \\
\hline Step 5 & 2512 & 7918 9001 & $5.82 \sim 6.90$ & $\mathrm{R}$ \\
\hline Step 6 & 2302 & $13660 \sim 15880$ & $10.49 \sim 12.19$ & $\mathrm{R}$ \\
\hline Step 7 & 2373 & $15380 \sim 21120$ & $12.97 \sim 18.73$ & $\mathrm{U}$ \\
\hline
\end{tabular}

"N": normal; "R": recoverable frequency jumping; "U": unrecoverable frequency deviation.

system in the experiment; thus, the magnitude of the loads cannot be controlled exactly, especially when the ASRS exceeds $10000 \mathrm{~g}$.

However, through analyzing the change trends of the experiment results, these two failure modes do exist commonly on both boards, i.e., frequency jumping and frequency deviation, which agrees well with the theoretical analysis in this paper.
4.2. Failure Mode 1: Frequency Jumping. During the loading process according to Table 1, the output signals of crystal oscillators on the C1 board are shown in Figure 12, in which the frequency jumping of No. 2 and No. 4 exceeds the threshold. It should be noted that after the impact loading process, both of these two crystal oscillators return to normal. 

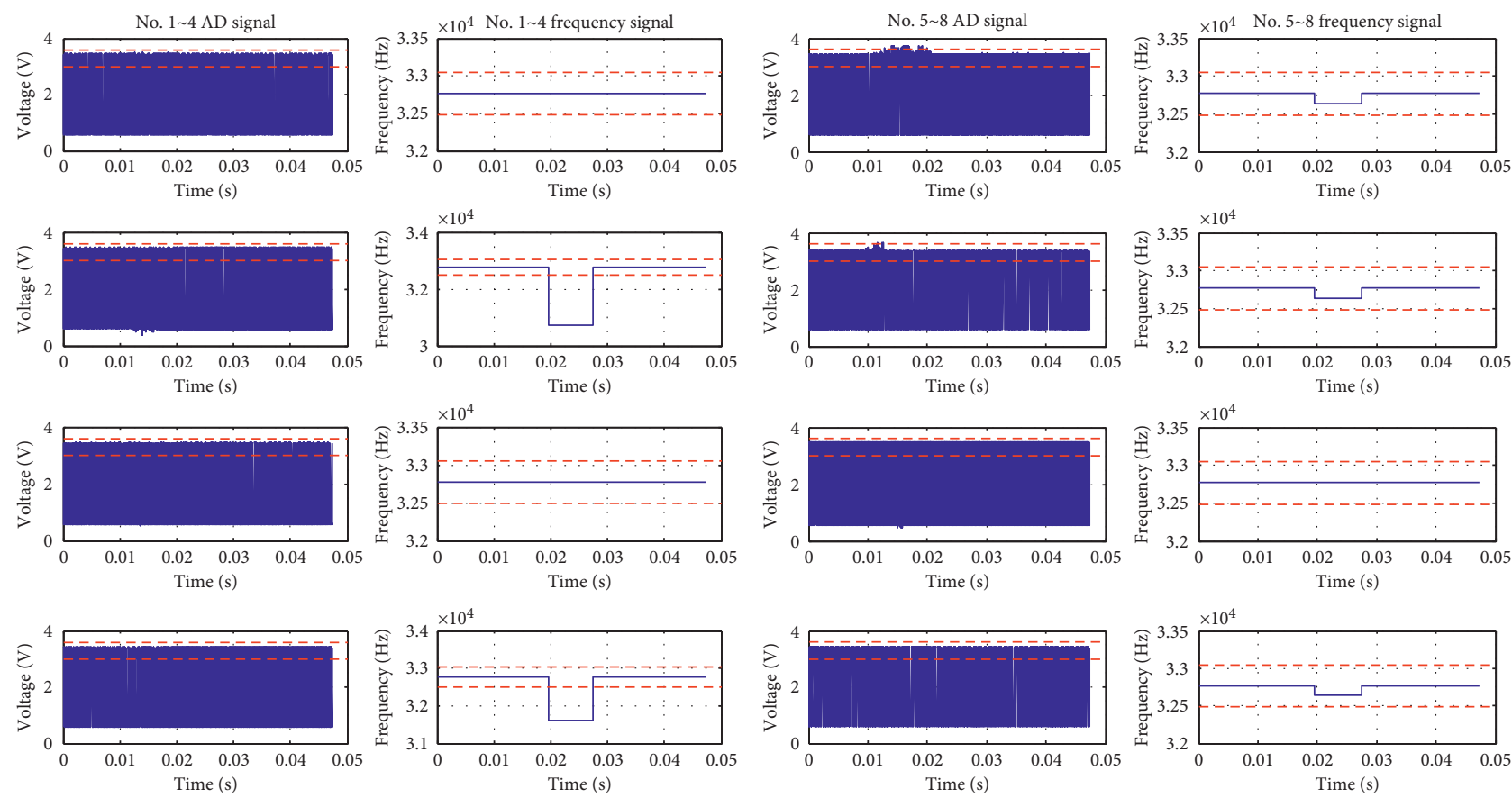

FiguRE 12: Electrical performance of the crystal oscillators on test board C1.
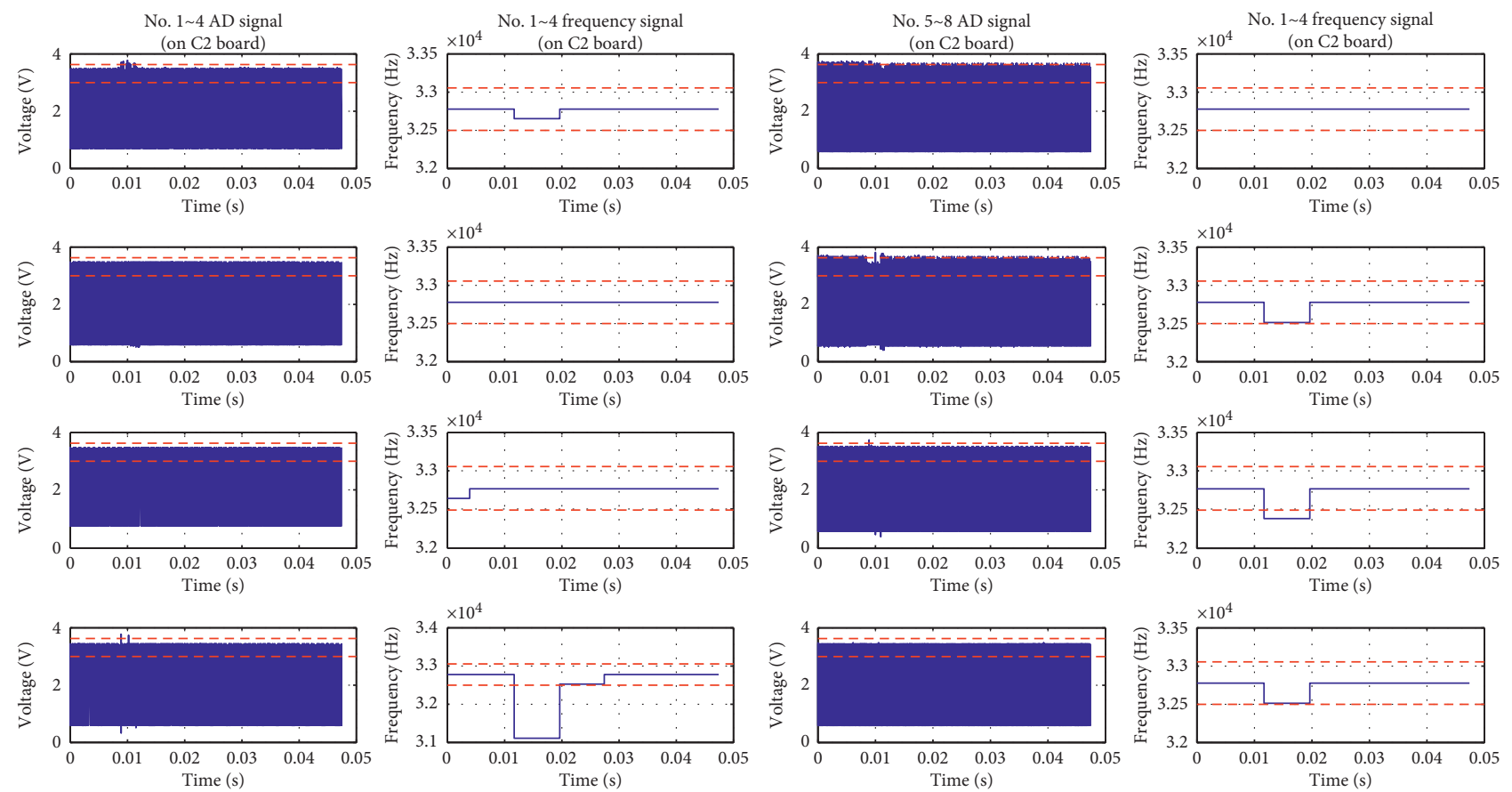

FIGURE 13: Electrical performance of the crystal oscillators on test board C2.

During the loading process with the condition of Table 2, the crystal frequency jumping of No. 4 and No. 7 on test board C2 also exceeds the threshold temporarily, as shown in Figure 13.

When the "frequency jumping" failure mode occurs, the comparisons of ASRS and PVSRS on C1 and C2 board are shown in Figures 14 and 15, respectively. When this failure mode occurs, the peak values of ASRS and PVSRS are different on test boards $\mathrm{C} 1$ and $\mathrm{C} 2$, but the value at a certain frequency range $(>2500 \mathrm{~Hz}$ ) is similar (about $2500 \mathrm{~g}$ ). Thus, the damage boundary for this failure mode can be expressed as

$$
\left.\operatorname{ASRS}_{c 1}\right|_{f>2500 \mathrm{~Hz}}=2500 \mathrm{~g} \text {. }
$$




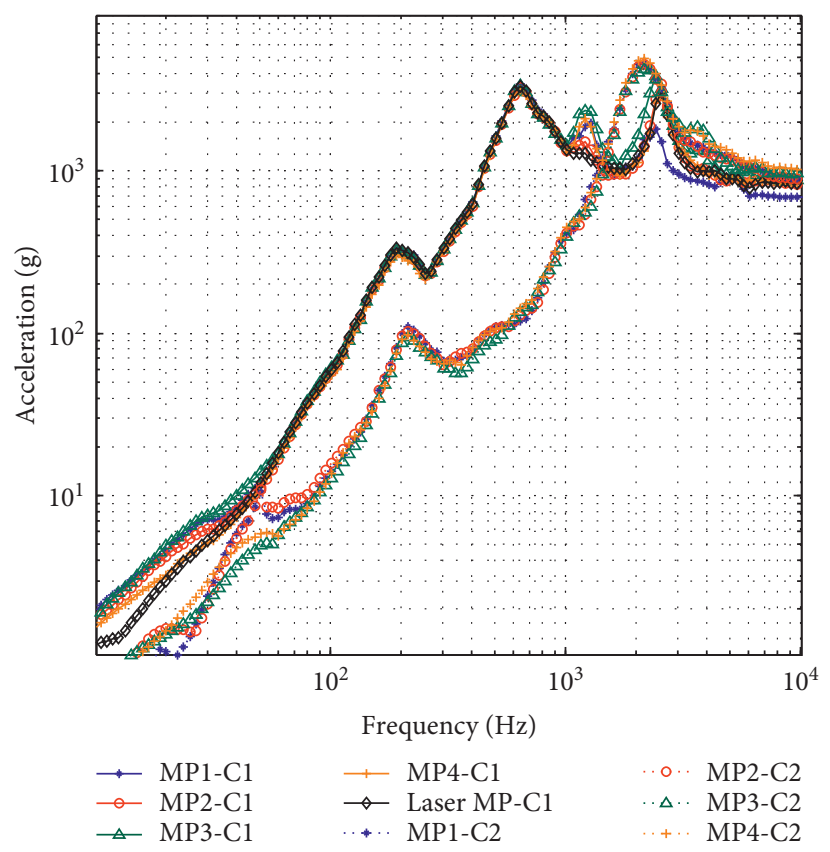

Figure 14: Acceleration shock response spectrums on C1 and C2.

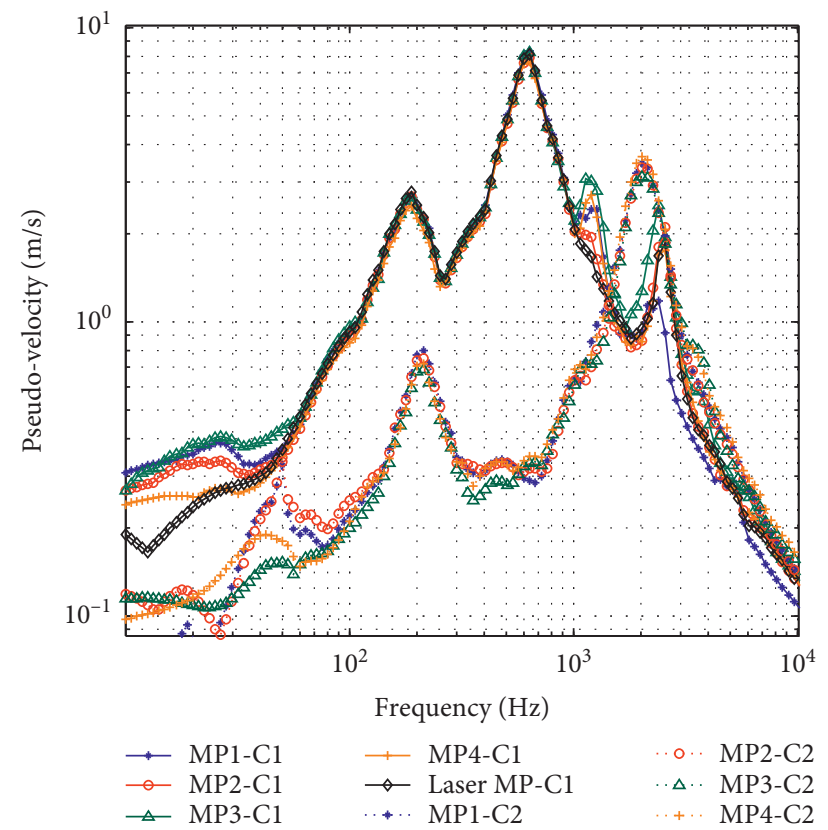

FIgURE 15: Pseudovelocity shock response spectrums on C1 and C2.

The "frequency jumping" failure mode of the crystal oscillator is a short-time failure at the impact moment, and the corresponding damage boundary is determined by the value of ASRS at the frequency range of $f>2500 \mathrm{~Hz}$. The response generated by the test device has a lower frequency than the working frequency of the crystal oscillator, so the working frequency tends to decrease at the impact moment, as shown in Figure 13.
4.3. Failure Mode 2: Structural Fracture. When the level of the shock excitation rises to a certain extent, the second failure mode will be monitored: the output frequency exceeds the threshold value and cannot return to normal after the loading process. Output signals on two test boards are shown in Figures 16 and 17.

The ASRS and PVSRS corresponding to the unrecoverable failure mode are shown in Figures 18 and 19. When 

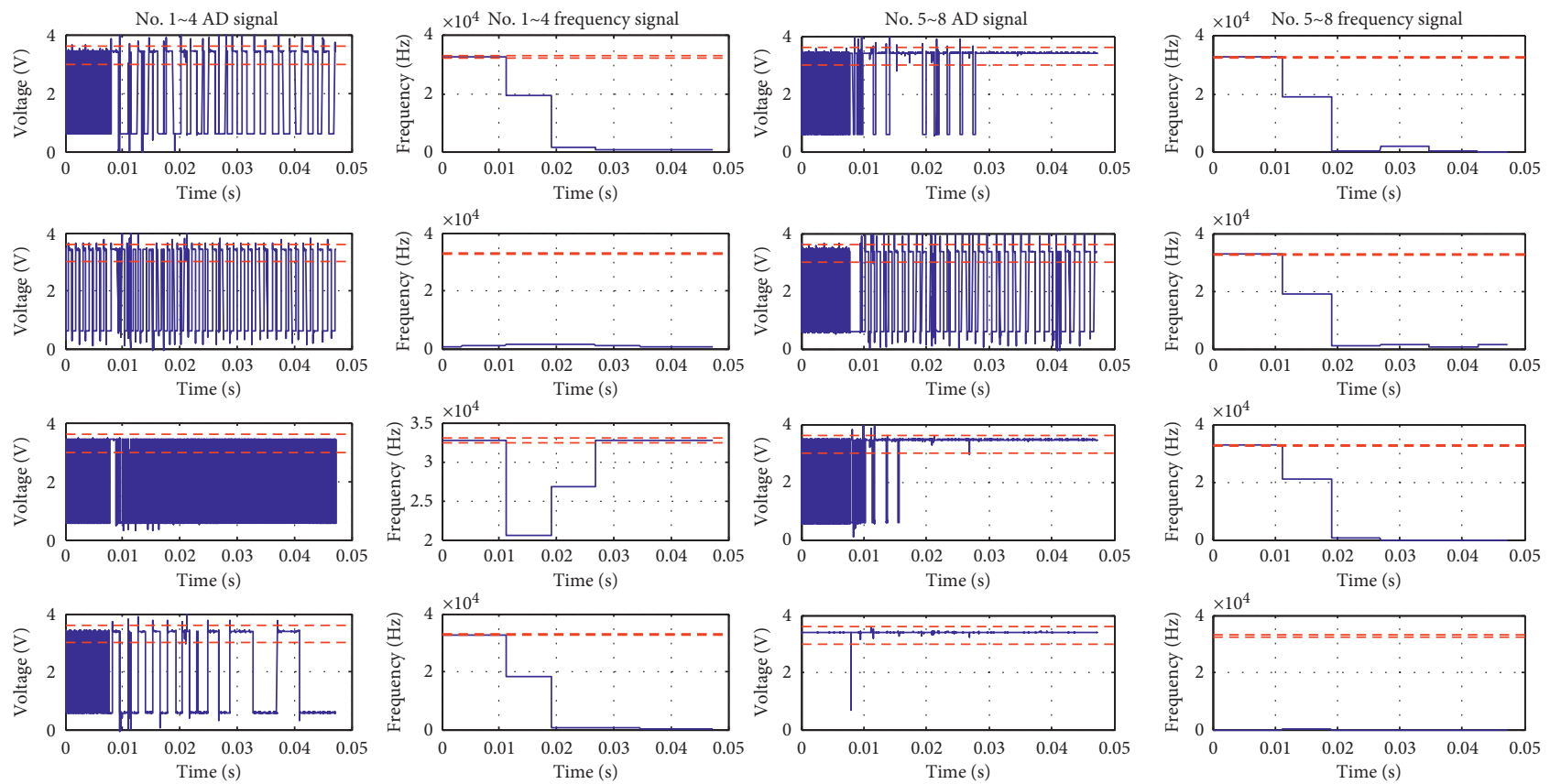

(a)
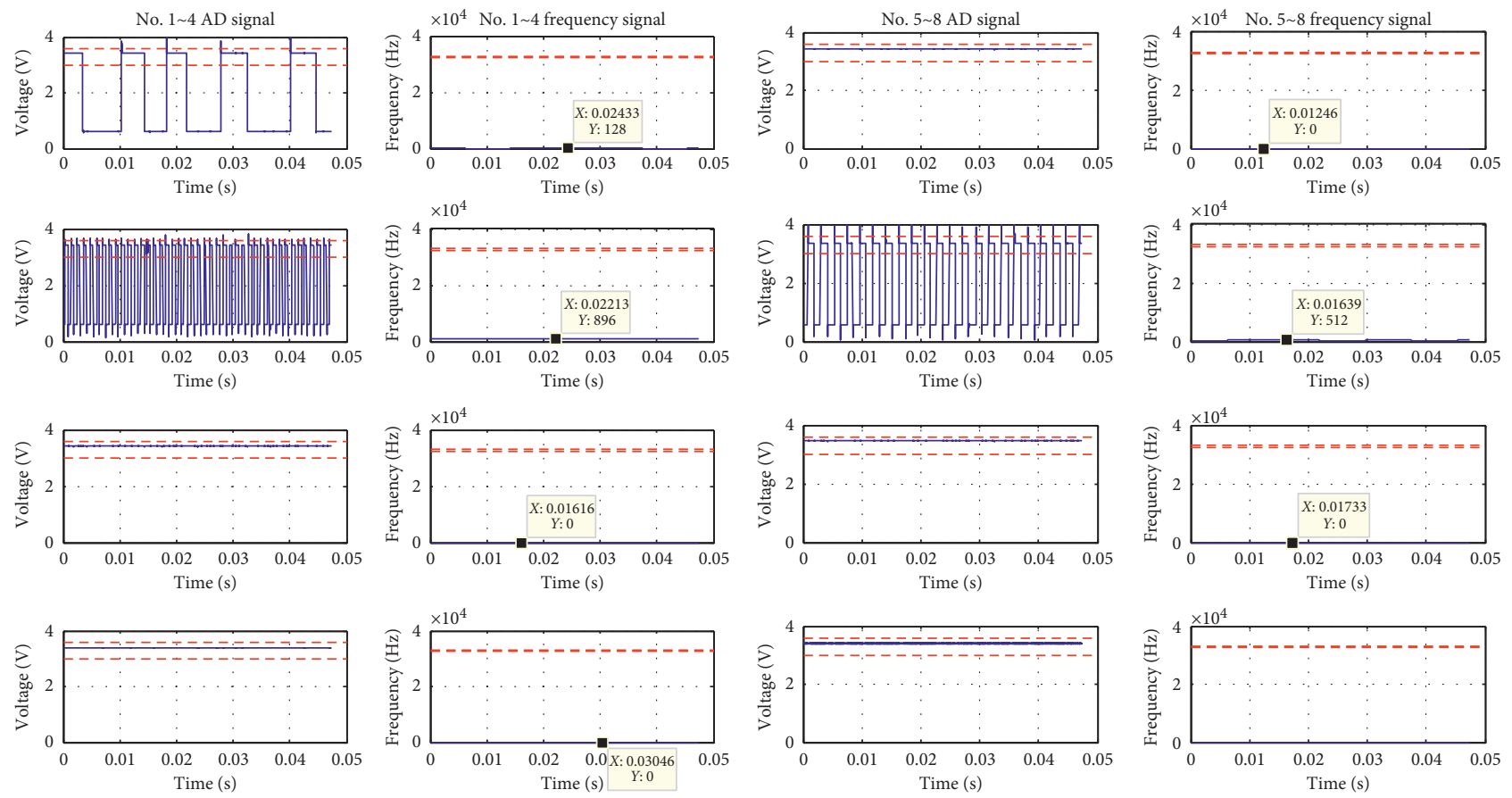

(b)

FIGURE 16: Electrical performance of the crystal oscillators on test board C1 under higher SRS. (a) Signals monitored during the loading process. (b) Signals monitored after the loading process.

this failure mode occurs, the ASRSs on $\mathrm{C} 1$ and $\mathrm{C} 2$ boards are similar, while the PVSRSs are quite different.

Through dissecting the specimens after the experiment, it is found that fracture occurs on the crystal plate, as shown in Figure 20, which leads to the permanent abnormal of the crystal oscillator.
The unrecoverable failure is caused by the high-level stress on the crystal plate and the damage boundary is determined by ASRS, which can be expressed as

$$
\max \left(\operatorname{ASRS}_{c 2}\right)=13000 \mathrm{~g}
$$



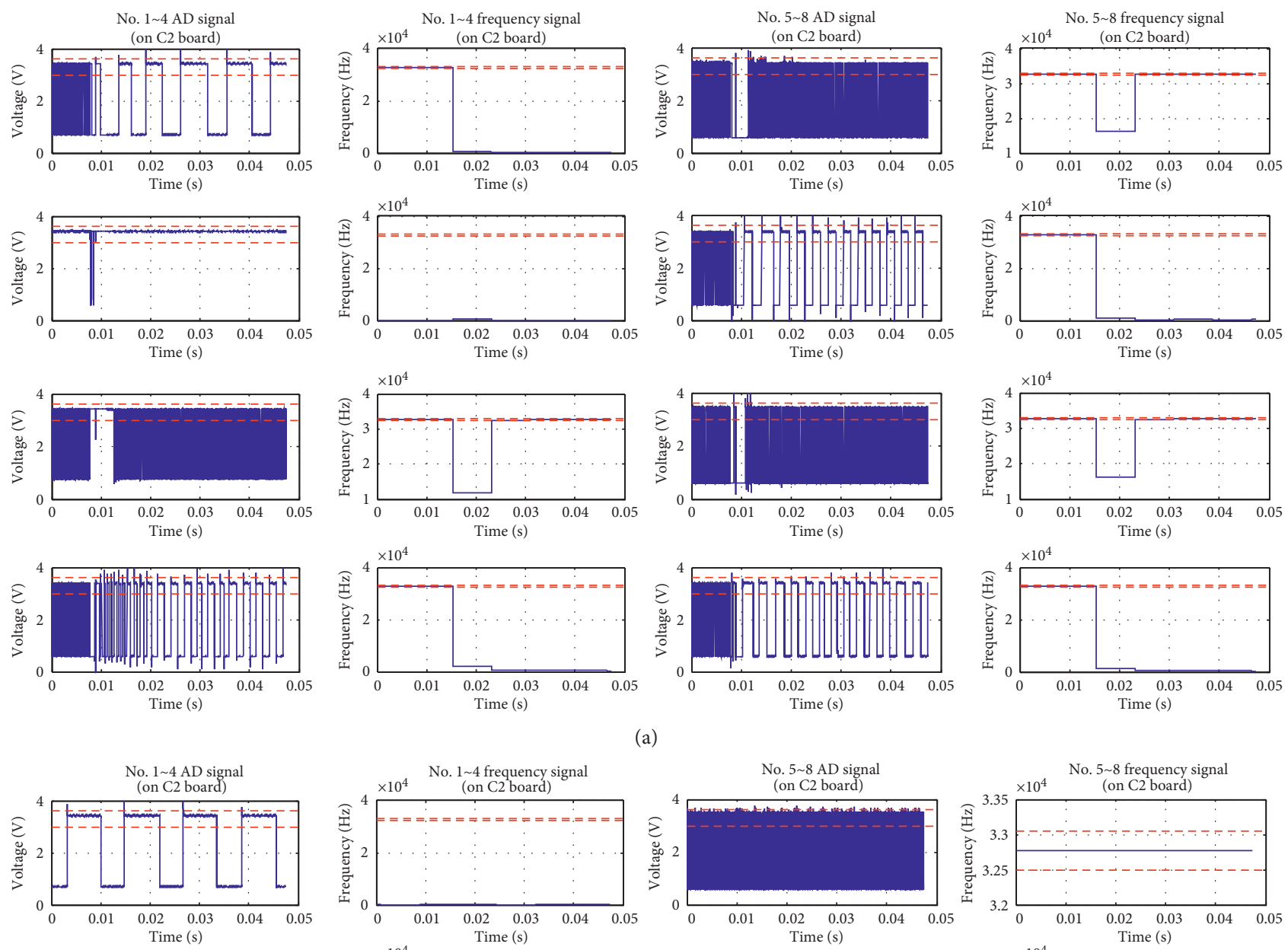

(a)
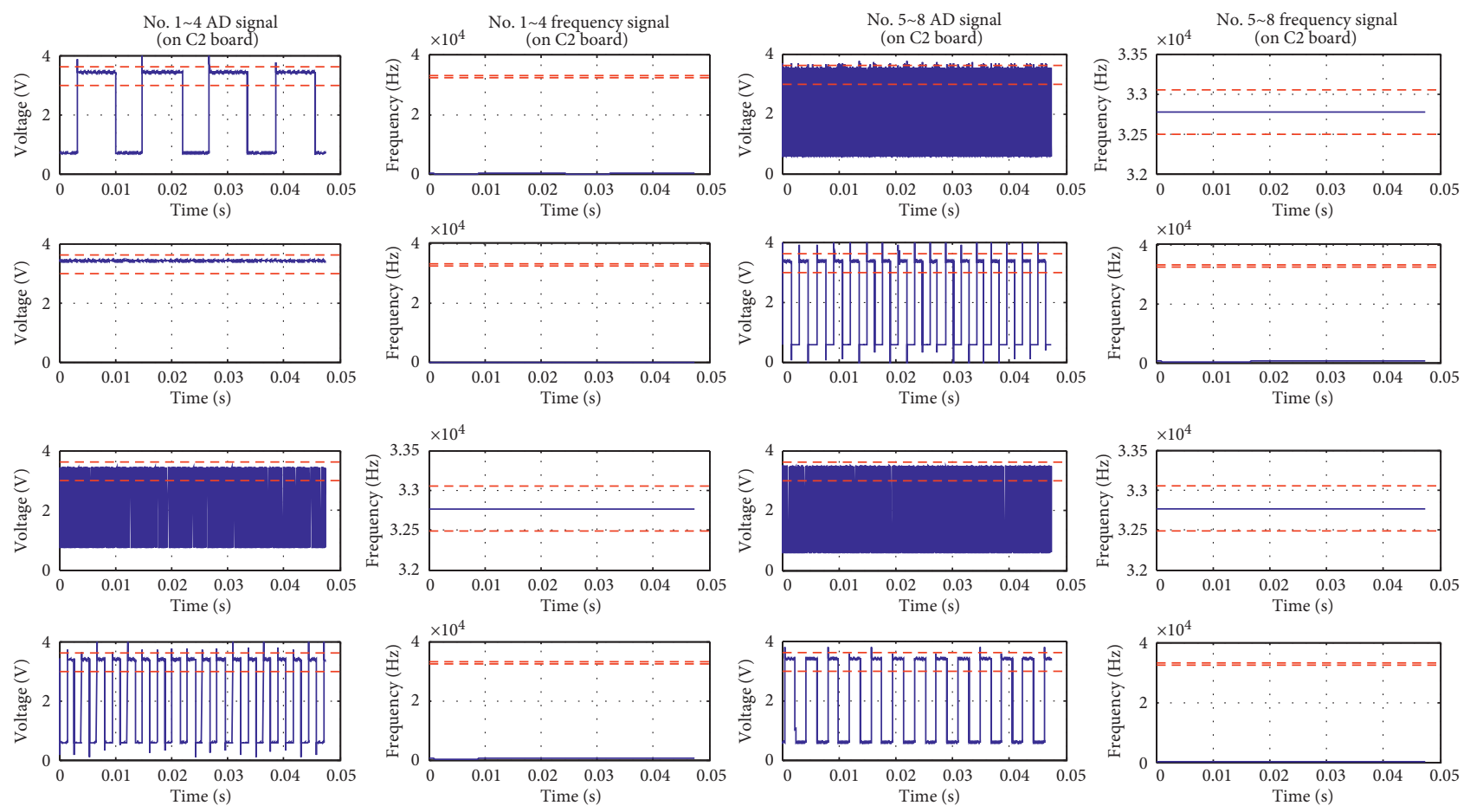

(b)

FIGURE 17: Electrical performance of the crystal oscillators on test board C2 under higher SRS. (a) Signals monitored during the loading process. (b) Signals monitored after the loading process.

As shown in Figure 18, the critical ASRS for "unrecoverable frequency deviation" is about $13000 \mathrm{~g}$. The "unrecoverable frequency deviation" failure mode is caused by the structural fracture of the crystal plate. As shown in
Figure 19, the structural damage of the crystal plate is caused by the high stress in the experiment. As shown in equation (2), the high stress in the crystal plate is related to the geometric profile, boundary conditions, and the peak value 


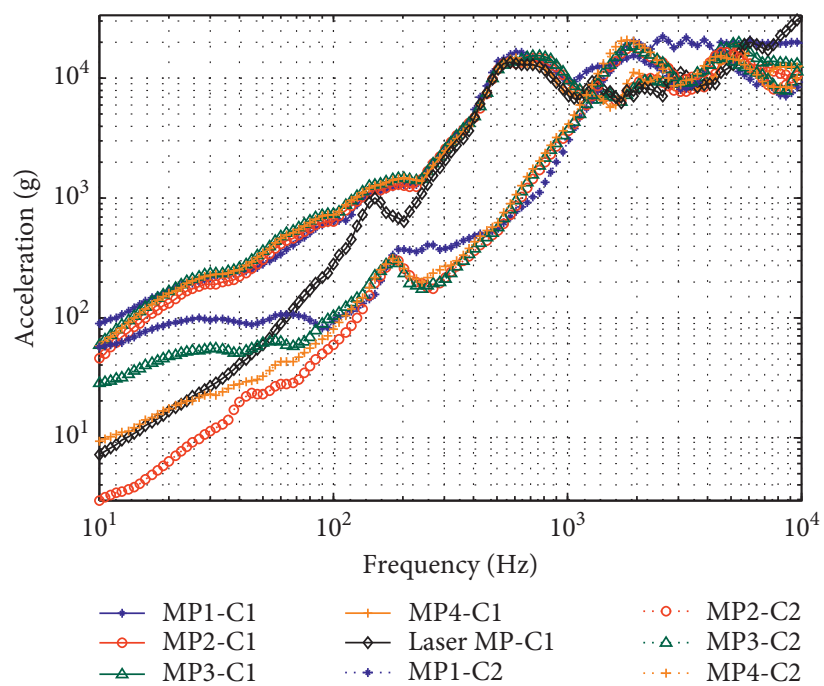

FIgURE 18: Acceleration shock response spectrums on $\mathrm{C} 1$ and C2 under higher SRS.

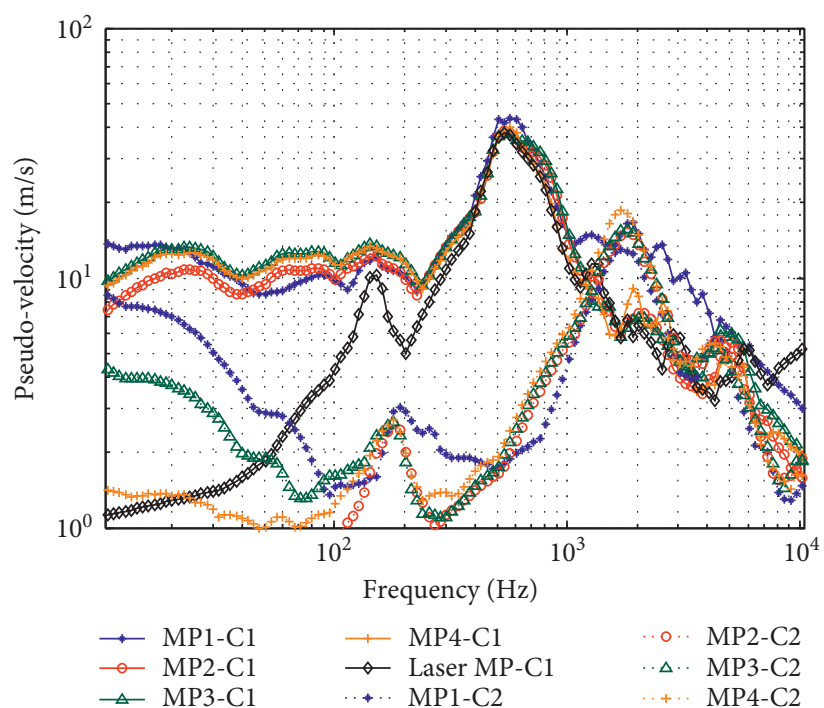

FIgURe 19: Pseudovelocity shock response spectrums on $\mathrm{C} 1$ and $\mathrm{C} 2$ under higher SRS.
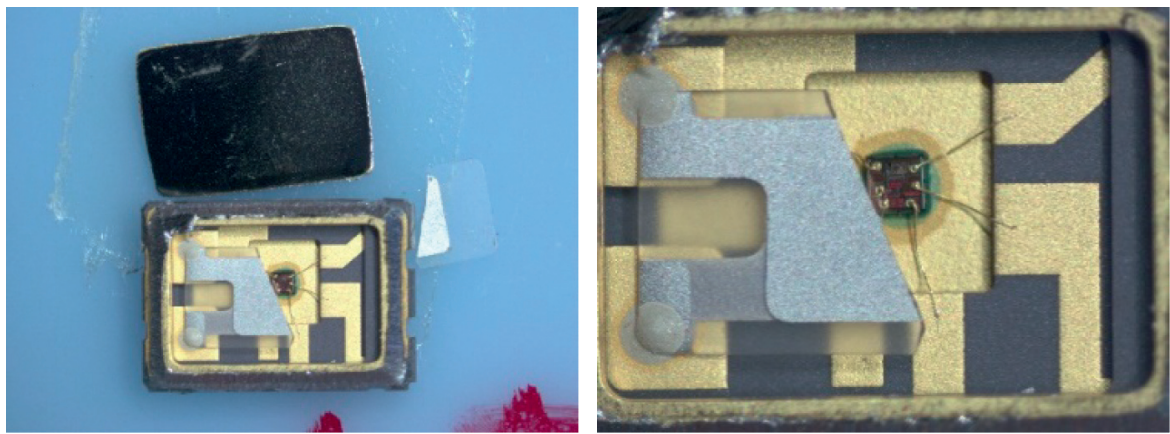

(a)

Figure 20: Continued. 

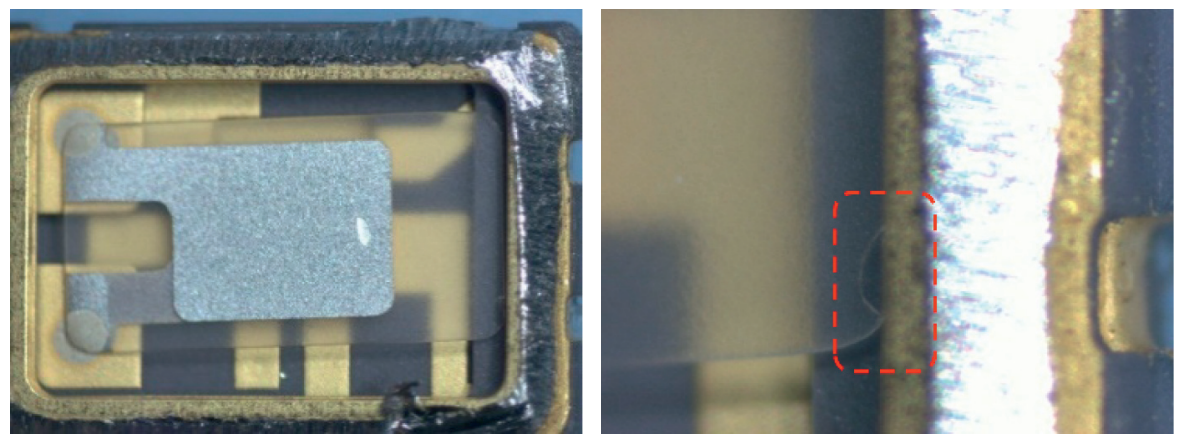

(b)

FIgURE 20: The fracture of the specimens after the experiment. (a) Specimen on C1 board. (b) Specimen on C2 board.

of the ASRS. Hence, the "unrecoverable frequency deviation" failure mode is governed by the ASRS, which agrees with the experimental results.

4.4. Failure not Governed by PVSRS. Both of the two failure modes monitored in the experiment are not governed by PVSRS, which agrees with the damage boundary theory proposed by $\mathrm{Li}$ [21]. The working frequency of the crystal oscillator is $32768 \mathrm{~Hz}$, which is much higher than the dominant frequency of the external excitation. It should be noted that the external excitation applied to the crystal oscillator is the response of the PCB caused by shock loads. Hence, the shock environment transferred to the crystal oscillator contains a dominant frequency related to the dynamical response of the $\mathrm{PCB}$, which is lower than the working frequency of the crystal oscillator.

\section{Conclusion}

In this paper, a mechanical model of the crystal oscillator is established, based on which two failure modes are discussed. The damage boundary is verified through a "step-up loading" experiment. The failure modes monitored in the experiment agree well with the theoretical analysis. Through analyzing the results of the experiment, the following conclusions can be obtained:

(a) The "frequency jumping" failure mode of the crystal oscillator is governed by ASRS in a certain frequency range, and the damage boundary can be expressed as $\left.\operatorname{ASRS}_{c 1}\right|_{f>2500 \mathrm{~Hz}}=2500 \mathrm{~g}$

(b) The "structural fracture" failure mode is governed by the peak value of ASRS, and the damage boundary can be expressed as $\max \left(\operatorname{ASRS}_{c 2}\right)=13000 \mathrm{~g}$

(c) The failure of the crystal oscillator is not governed by PVSRS, because the dominant frequency of the shock excitation is far away from the working frequency of the crystal oscillator

This research can provide methods for failure assessment of electronic components and also provide a reference for the research of dynamical response structures under shock environment.

\section{Data Availability}

The data used to support the findings of this study are included within the article.

\section{Conflicts of Interest}

The authors declare that there are no conflicts of interest regarding the publication of this paper.

\section{Acknowledgments}

This paper was supported by the National Natural Science Foundation of China (Nos. 11972377 and 11902364) and the Opening Project of State Key Laboratory of Explosion Science and Technology (Beijing Institute of Technology) (No. KFJJ19-04M).

\section{References}

[1] L. Le, Z. Jing, and X. Peng, "Failure mechanism of crystal oscillator EXO3 and KSS under high shock," China Measurement Technology, no. 3, pp. 88-90, 2007.

[2] Q. Shi-Qi, N. Shao-Hua, and G. Shi-Qiao, "Failure mechanism analysis of quartz crystal oscillators under impact load," Acta Armamentarii, no. S2, pp. 96-100, 2016.

[3] X. Peng, "Failure mechanical analysis of crystal oscillator under high g acceleration," Journal of North University of China, no. 4, pp. 424-428, 2010.

[4] S. B. Menkes and H. J. Opat, "Broken beams," Experimental Mechanics, vol. 13, no. 11, pp. 480-486, 1973.

[5] R. G. Teeling-Smith and G. N. Nurick, "The deformation and tearing of thin circular plates subjected to impulsive loads," International Journal of Impact Engineering, vol. 11, no. 1, pp. 77-91, 1991.

[6] M. D. Olson, G. N. Nurick, J. R. Fagnan et al., "Deformation and rupture of blast loaded square plates-predictions and experiments," International Journal of Impact Engineering, vol. 13, no. 2, pp. 279-291, 1993.

[7] N. Jones, "Plastic failure of ductile beams loaded dynamically," Journal of Engineering for Industry, vol. 98, no. 1, pp. 131-136, 1976.

[8] W. Q. Shen and N. Jones, "A failure criterion for beams under impulsive loading," International Journal of Impact Engineering, vol. 12, no. 1, pp. 101-121, 1992. 
[9] H. M. Wen, T. X. Yu, T. Y. Reddy et al., "Failure maps of clamped beams under impulsive loading," Mechanics of Structures and Machines, vol. 23, no. 4, pp. 453-472, 1995.

[10] H. M. Wen, T. X. Yu, T. Y. Reddy et al., "A note on clamped circular plates under impulsive loading," Mechanics of Structures and Machines, vol. 23, no. 3, pp. 331-342, 1995.

[11] H. M. Wen, T. Y. Reddy, S. R. Reid et al., "Deformation and failure of clamped beams under low speed impact loading," International Journal of Impact Engineering, vol. 16, no. 3, pp. 435-454, 1995.

[12] ANSI/ASA-S2 62-2009, Shock Test Requirements for Equipment in a Rugged Shock Environment, American National Standards Institute, Inc., American Society of Acoustics, New York, NY, USA, 2009.

[13] L. J. Lu, A. J. Ma, and X. M. Feng, "A review of shock response spectrum test standard," Journal of Vibration and Shock, vol. 21, no. 2, pp. 18-20, 2002.

[14] X. F. Yang, Y. Q. Zou, W. H. Deng et al., "An approach to evaluate high level shock for aerospace units," Journal of Astronautics, no. 8, pp. 872-878, 2017.

[15] H. A. Gaberson, "Pseudo velocity shock spectrum rules for analysis of mechanical shock," in Proceedings of the IMAC $X X V$, Society of Experimental Mechanics, Orlando, FL, USA, May 2007.

[16] H. A. Gaberson, "Shock severity estimation," Sound and Vibration, vol. 46, no. 1, pp. 12-19, 2012.

[17] T. Irvine, "Shock severity limits for electronic component," Rev D, Vibration Data, pp. 1-22, 2014.

[18] T. Irvine, "Shock and vibration stress as a function of velocity," Rev G, Vibration Data, pp. 1-76, 2013.

[19] T. Irvine, "Using a random vibration test specification to cover a shock requirement via a pseudo velocity fatigue damage spectrum," Procedia Engineering, vol. 101, pp. 211$218,2015$.

[20] H. A. Gaberson, D. Pal, and R. S. Chapler, "Classification of violent environments that cause equipment failure," Sound and Vibration, vol. 34, no. 5, pp. 16-23, 2000

[21] B. W. Li and Q. M. Li, "Damage boundary of structural components under shock environment," International Journal of Impact Engineering, vol. 118, pp. 67-77, 2018. 